\title{
CD16 expression on neutrophils predicts treatment efficacy of capecitabine in colorectal cancer patients
}

Yu Lu ${ }^{1+}$, Yizhou Huang ${ }^{2+}$, Lei Huang ${ }^{3+}$, Yanjie Xu ${ }^{3}$, Zien Wang ${ }^{3}$, Han $\mathrm{Li}^{3}$, Ting Zhang ${ }^{3}$, Ming Zhong ${ }^{2^{*}}$, Wei-qiang Gao ${ }^{1,3^{*}}$ and Yan Zhang ${ }^{1,3^{*}}$ (D)

\begin{abstract}
Background: Early detection of capecitabine-resistance could largely increase overall survival of colorectal cancer (CRC) patients. Previous studies suggested examination of immune cells in peripheral blood would help to predict efficacy of chemotherapy.

Methods: We examined the immunological characteristics of peripheral blood in CRC patients with capecitabine treatment. We analyzed the relationships between the abnormal immune cell population in capecitabine-resistance patients and major clinical features. Furthermore, RNA sequencing, analyses of cell surface marker expression and the correlations with other major immune cell populations were performed using this population to explore the possible function of these cells.

Results: The expression level of CD16 on neutrophils was down-regulated in capecitabine-resistant CRC patients. Patients with $\mathrm{CD} 16^{\mathrm{low} /}$ - neutrophils after capecitabine therapy had adverse clinical features. What's important, the change of CD16 expression level on neutrophils appeared much earlier than CT scan. RNA sequencing revealed that CD16 ${ }^{\text {low/- }}$ neutrophils in capecitabine-resistant patients had lower expression level of neutrophil-related genes, compared to $C D 16^{+}$neutrophils in capecitabine-sensitive patients, suggesting this $C D 16^{\text {low/- }}$ population might be immature neutrophils. Furthermore, the expression level of CD16 on neutrophils in patients with capecitabine treatment was positively correlated with the number of anti-tumor immune cell subsets, such as CD8 ${ }^{+} T$ cell, $C D 4^{+} T$ cell, NK cell and monocyte.
\end{abstract}

Conclusions: Our findings indicated that CD16 expression on neutrophils in peripheral blood was a good prognostic marker for predicting efficacy of capecitabine in CRC patients.

Keywords: CD16, Neutrophils, Capecitabine-resistance, Colorectal cancer

\footnotetext{
* Correspondence: drzhongming1966@163.com; gao.weiqiang@sjtu.edu.cn; yanzh@sjtu.edu.cn

Yu Lu, Yizhou Huang and Lei Huang share first authorship.

2Department of Gastrointestinal Surgery, Renji Hospital, School of Medicine,

Shanghai Jiaotong University, Shanghai, China

'State Key Laboratory of Oncogenes and Related Genes, Renji-Med X Stem

Cell Research Center, Renji Hospital, School of Medicine, Shanghai Jiaotong University, Shanghai, China

Full list of author information is available at the end of the article
}

(c) The Author(s). 2020 Open Access This article is licensed under a Creative Commons Attribution 4.0 International License, which permits use, sharing, adaptation, distribution and reproduction in any medium or format, as long as you give appropriate credit to the original author(s) and the source, provide a link to the Creative Commons licence, and indicate if changes were made. The images or other third party material in this article are included in the article's Creative Commons licence, unless indicated otherwise in a credit line to the material. If material is not included in the article's Creative Commons licence and your intended use is not permitted by statutory regulation or exceeds the permitted use, you will need to obtain permission directly from the copyright holder. To view a copy of this licence, visit http://creativecommons.org/licenses/by/4.0/ The Creative Commons Public Domain Dedication waiver (http://creativecommons.org/publicdomain/zero/1.0/) applies to the data made available in this article, unless otherwise stated in a credit line to the data. 


\section{Background}

Colorectal cancer (CRC) is one of the leading cause of death worldwide. More than 1.8 million patients are diagnosed with CRC every year [1-3]. What's more, this lifethreaten disease kills nearly 0.9 million people annually [1]. In north America and Europe, the morbidity and mortality remain at high level [1], despite developments of cancer screening and endoscopy $[2,3]$. In China, CRC becomes the 5th most diagnosed cancer and 5th most deadly cancer [4-6]. Nearly 0.4 million new cases are diagnosed and about 0.2 million people die from the disease every year [6].

Postoperative adjuvant chemotherapy is first-line treatment for CRC patients [7, 8]. Capecitabine, a carbamate derivative of fluoropyrimidine, is the backbone of CRC chemotherapy $[9,10]$. As the oral prodrug of 5fluorouracil (5-FU), it is widely used for postoperative adjuvant chemotherapy due to its long, stable duration, lower toxicity and convenient dosing compared to infusional 5-FU [7, 11]. However, this chemotherapeutic drug has only modest efficacy, the response rates of 5-FU for advanced CRC is only $15 \%$ for single treatment and $50 \%$ for combined chemotherapy $[12,13]$. The chemoresistance is recognized as a principal obstacle for cancer therapy [14-16], leading to tumor recurrence or metastasis, especially liver and lung metastasis, and cause over $90 \%$ of CRC mortality [17]. Intense researches on the mechanisms underlying the resistance revealed that changes of tumor cells themselves cause resistance, although these findings are mainly restricted to tumor specimen examine, which is not that suitable for post-treatment surveillance. What's more, CT (computed tomography) scan and colonoscopy are insensitive to micro metastasis, despite their good accuracy for the detection of recurrence. Capecitabine-resistant patients could only be diagnosed with cancer recurrence by $\mathrm{CT}$ scan or colonoscopy about 2-3 years after capecitabine therapy [18], when tumors are big enough to be discovered. Thus, good prognostic markers are indispensable for predicting capecitabineresistance in the early stage after capecitabine therapy.

Cancer cells and their microenvironment could interact with each other. Immune cells could dynamically reflect cancer status and display multifaceted functions in cancer development [19-22]. Myeloid cells, including monocytes, macrophages, granulocytes (neutrophils, eosinophils, basophils) and mast cells, play critical roles in cancer progression [19-22]. Myeloid-derived suppressor cells (MDSCs), a heterogeneous population of myeloid cells remain at different stages of differentiation, are immature counterparts of myeloid cells in cancer. MDSCs acquire immunosuppressive features and mainly inhibit lymphocytes, including $\mathrm{T}$ cells and NK cells [23-25]. Recent studies report that chemotherapeutic agents, like 5-FU, could interact with myeloid cells, and influence anti-tumor efficacy [26-29]. Vincent $\mathrm{J}$ et al. reported that 5-FU selectively induced
MDSC apoptotic cell death and increase IFN- $\gamma$ production by tumor-specific $\mathrm{CD}^{+} \mathrm{T}$ cells [26]. Other researchers showed that activation of NLRP3 inflammasome and increased amount of HSP70 exosomes on MDSC by 5-FU lead to MDSC activation [27, 28]. Yuan Y et al. found that tumor-associated macrophages secret IL-6 to induce 5-FU chemoresistance [29].

In this study, we discovered that the expression of CD16 on $\mathrm{CD} 11 \mathrm{~b}^{+}$myeloid cells was dramatically decreased in capecitabine-resistant CRC patients after capecitabine adjuvant therapy. The expression level of CD16 was closely related to poor prognosis after capecitabine therapy. Importantly, the down-regulation of $\mathrm{CD} 16$ on $\mathrm{CD} 11 \mathrm{~b}^{+}$myeloid cells appeared as early as 1 month after capecitabine therapy in patients who were diagnosed with capecitabine-resistance by CT scans about 2-3 years after the treatment. The cut-off value of CD16 expression (3.8\%) would be helpful for the prediction of capecitabine chemoresistance. Further analysis demonstrated that these $\mathrm{CD} 11 \mathrm{~b}^{+} \mathrm{CD} 16^{\text {low/-}}$ myeloid cells were mainly immature neutrophils and expression level of CD16 on neutrophils had a positive relationship with frequencies of anti-tumor immune cell populations, such as $\mathrm{CD} 8^{+} \mathrm{T}$ cells and NK cells.

\section{Results \\ CD16 expression levels on CD11 $\mathrm{b}^{+}$myeloid cells in peripheral blood of capecitabine-resistant CRC patients are different from capecitabine-sensitive CRC patients after capecitabine therapy}

To explore if myeloid cells in peripheral blood could predict the treatment efficacy of capecitabine, we chose 36 CRC patients with capecitabine adjuvant treatment whose immune cells populations in peripheral blood were examined by flow cytometry before and about 6-9 months after the treatment. Patients were divided into capecitabinesensitive and capecitabine-resistant groups, based on the diagnosis of recurrence by CT scan in about 2-3 years after capecitabine treatment (Table 1, Additional file 1: Fig. S1E). No significant change was observed in major myeloid cell subsets, such as monocytes $\left(\mathrm{CD} 11 \mathrm{~b}^{+} \mathrm{CD} 14^{+} \mathrm{CD} 15^{-}\right)$, neutrophils $\left(\mathrm{CD} 11 \mathrm{~b}^{+} \mathrm{CD} 15^{+} \mathrm{CD} 14^{-}\right.$or $\left.\mathrm{CD} 11 \mathrm{~b}^{+} \mathrm{CD} 66 \mathrm{~b}^{+} \mathrm{CD} 14^{-}\right)$ and MDSCs $\left(\mathrm{CD} 11 \mathrm{~b}^{+}\right.$HLA-DR $\left.{ }^{- \text {llow }} \mathrm{CD}^{+} 3^{+}\right)$, between capecitabine-sensitive patients and capecitabine-resistant patients (Additional file 1: S1A, B, C and D). But we found

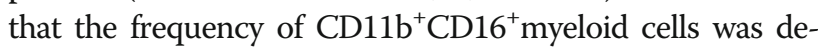
creased in capecitabine-resistant patients after capecitabine treatment compared to that before the treatment (Fig. 1a). What's important, a dramatic lower expression level of

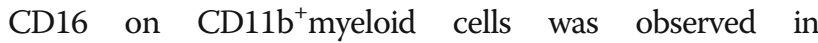
capecitabine-resistant patients, compared to that of drugsensitive patients. Patient 1 and patient 27 are representative patients from capecitabine-sensitive group and capecitabine-resistant group, respectively (Fig. 1b). The 
Table 1 Baseline characteristics of CRC patients in Fig. 1

\begin{tabular}{|c|c|c|c|c|c|c|c|c|}
\hline Group & Number of Patients & Age & Sex & TNM Stage & Location & CEA (ng/ml) & CA199 (ng/ml) & $\begin{array}{l}\text { Diagnosis of Recurrence After } \\
\text { Capecitabine Treatment }\end{array}$ \\
\hline \multirow[t]{26}{*}{ Capecitabine-sensitive } & 1 & 40 & M & $\|$ & Rectum & 1.9 & 0.6 & No \\
\hline & 2 & 62 & M & $\|$ & Rectum & 7.83 & 12.44 & No \\
\hline & 3 & 56 & M & $\|$ & Colon & 1.71 & 24.79 & No \\
\hline & 4 & 67 & M & $\|$ & Colon & 1.56 & 0.24 & No \\
\hline & 5 & 81 & M & $\|$ & Rectum & 4.06 & 19.04 & No \\
\hline & 6 & 32 & $\mathrm{~F}$ & $\|$ & Rectum & 4 & 4.02 & No \\
\hline & 7 & 50 & $\mathrm{~F}$ & $\|$ & Rectum & 3.31 & 15.57 & No \\
\hline & 8 & 62 & $\mathrm{~F}$ & $\|$ & Colon & 2.41 & 3.57 & No \\
\hline & 9 & 52 & M & $\|$ & Rectum & 4.3 & 19.58 & No \\
\hline & 10 & 44 & $\mathrm{~F}$ & $\|$ & Colon & 1.59 & 11.67 & No \\
\hline & 11 & 72 & M & $\|$ & Colon & 4.44 & 17.52 & No \\
\hline & 12 & 21 & $\mathrm{~F}$ & $\|$ & Colon & 1.25 & 6.48 & No \\
\hline & 13 & 53 & M & $\|$ & Rectum & 1.06 & 20.42 & No \\
\hline & 14 & 63 & M & III & Colon & 0.8 & 16.51 & No \\
\hline & 15 & 43 & M & $\|$ & Rectum & 1.08 & 0.9 & No \\
\hline & 16 & 55 & $\mathrm{~F}$ & $\|$ & Rectum & 1.18 & 4 & No \\
\hline & 17 & 46 & M & $\|$ & Rectum & 4.92 & 18.26 & No \\
\hline & 18 & 69 & M & $\|$ & Rectum & 0.89 & 23 & No \\
\hline & 19 & 70 & $\mathrm{~F}$ & $\|$ & Colon & 4.28 & 8.01 & No \\
\hline & 20 & 71 & $\mathrm{~F}$ & $\|$ & Colon & 4.62 & 20.58 & No \\
\hline & 21 & 64 & $\mathrm{~F}$ & $\|$ & Rectum & 2.2 & 19.31 & No \\
\hline & 22 & 72 & M & $\|$ & Rectum & 1.19 & 2.28 & No \\
\hline & 23 & 61 & $\mathrm{~F}$ & $\|$ & Rectum & 8.81 & 4.4 & No \\
\hline & 24 & 62 & M & $\|$ & Rectum & 1.92 & 28 & No \\
\hline & 25 & 50 & $\mathrm{~F}$ & III & Colon & 3.65 & 16.42 & No \\
\hline & 26 & 65 & M & III & Rectum & 3.72 & 15.39 & No \\
\hline \multirow[t]{10}{*}{ Capecitabine-resistant } & 27 & 63 & M & $\|$ & Rectum & 3.16 & 12.47 & Yes \\
\hline & 28 & 70 & M & III & Colon & 5.28 & 11.1 & Yes \\
\hline & 29 & 57 & M & III & Colon & 14.8 & 31.2 & Yes \\
\hline & 30 & 65 & $\mathrm{~F}$ & $\|$ & Rectum & 3.65 & 29.4 & Yes \\
\hline & 31 & 52 & M & $\|$ & Rectum & 4.3 & 30.9 & Yes \\
\hline & 32 & 49 & M & III & Rectum & 25.8 & 36.8 & Yes \\
\hline & 33 & 54 & M & III & Rectum & 16.2 & 36.16 & Yes \\
\hline & 34 & 54 & $\mathrm{~F}$ & III & Rectum & 29.74 & 53.2 & Yes \\
\hline & 35 & 45 & $\mathrm{~F}$ & $\|$ & Rectum & 14 & 6.7 & Yes \\
\hline & 36 & 59 & M & $\|$ & Colon & 4.37 & 12.4 & Yes \\
\hline
\end{tabular}

diagnosis of capecitabine resistance was determined by $\mathrm{CT}$ scan (Additional file 1: Fig. S1E). However, when we ana-

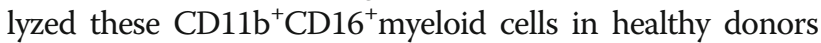
(HDs) and CRC patients before capecitabine therapy, we found no difference between these two cohorts (Additional file 1: Fig. S1F and G). This indicated that change of CD16

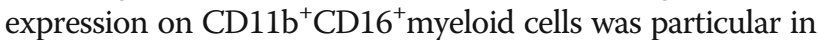
$\mathrm{CRC}$ patients who were resistant to capecitabine therapy.
Decreased CD16 expression is correlated with poor pathological features in CRC patients after capecitabine therapy

To determine whether the expression level of CD16 on $\mathrm{CD}_{11 \mathrm{~b}^{+}}$myeloid cells is related to treatment efficacy of capecitabine, we collected peripheral venous blood of 134 CRC patients 6-9 months after capecitabine treatment and divided these patients into two groups, $\mathrm{CD} 16^{+}$group and 

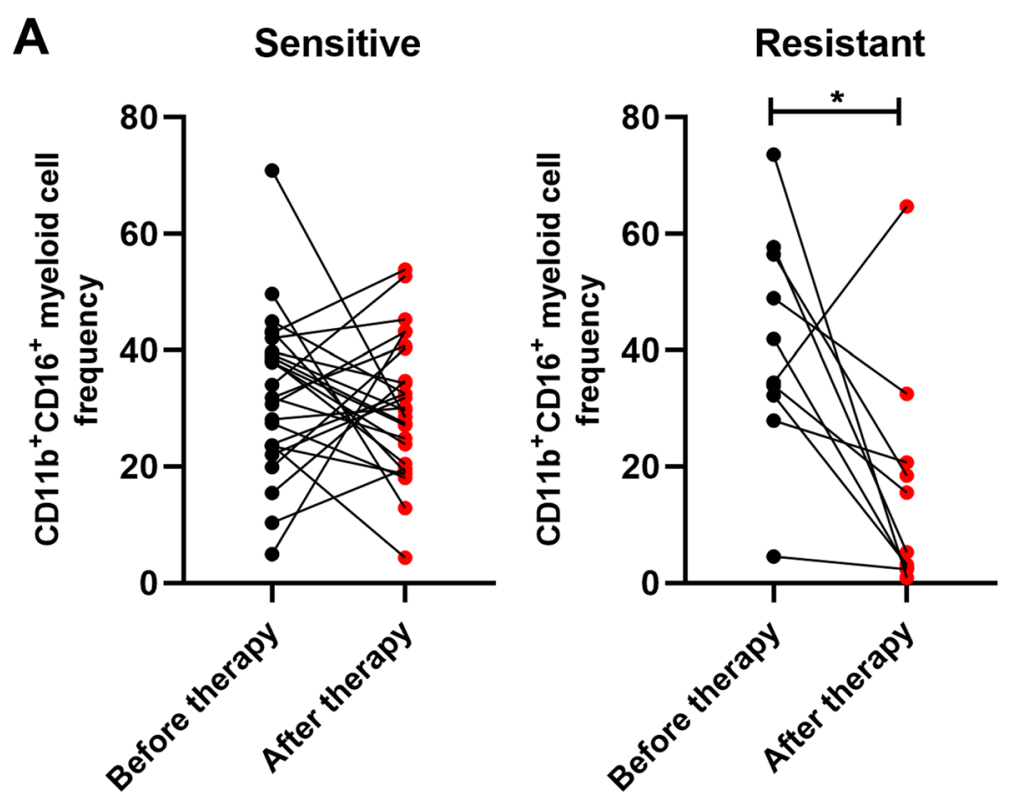

B

Patient 1

Patient 27
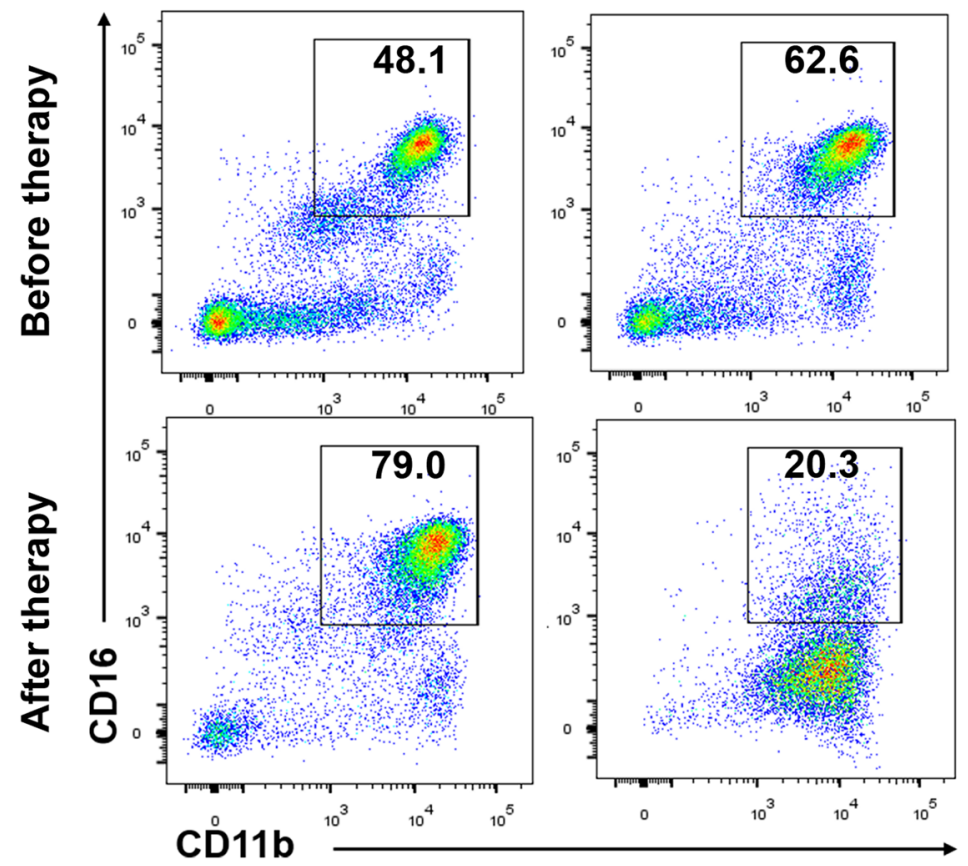

Fig. 1 CD16 expression of peripheral blood myeloid cells were differential in CRC patients after capecitabine therapy. Peripheral venous blood from CRC patients received single-agent oral capecitabine adjuvant therapy was collected before the therapy and 6-9 months after the therapy and analyzed for myeloid cell-related markers. (Attention: Blood were collected 6-9 months after capecitabine treatment unless particularly noted). a Frequencies of $\mathrm{CD} 11 \mathrm{~b}^{+} \mathrm{CD} 16^{+}$myeloid cells were compared before and after capecitabine therapy in capecitabine-sensitive and capecitabine-resistant patients ( $n=26$ in sensitive group and $n=10$ in resistant group, respectively). b Representative images of CD16 expression on CD11 b myeloid cells before and after capecitabine therapy in two CRC patients from capecitabine-sensitive group or capecitabine resistant group, respectively. Diagnosis of drug-resistance was proved by CT scan during the follow-up in Fig. S1e. Mean \pm SEM, ${ }^{*} P<0.05$ by $t$ tests (a)

CD16 ${ }^{\text {low/- }}$ group. Firstly, K-mean clustering algorithm was used to determine the boundary value to divide

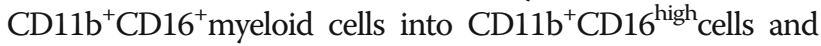

$\mathrm{CD}_{11 \mathrm{~b}^{+}} \mathrm{CD} 16^{\text {low }}$ cells, based on mean fluorescent intensity (MFI) of $\mathrm{CD} 16$ on $\mathrm{CD} 11 \mathrm{~b}^{+} \mathrm{CD} 16^{+}$myeloid cells in peripheral blood after capecitabine therapy (Additional file 2: Fig. S2A). 
The boundary value of CD16 MFI for division of

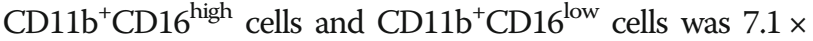
$10^{3}$. Next, we analyzed frequency of $\mathrm{CD} 11 \mathrm{~b}^{+} \mathrm{CD} 16^{\text {high }}$ cells in peripheral blood after capecitabine therapy (Additional file 2: Fig. S2B), and determined the cut-off value for CD16 ex-

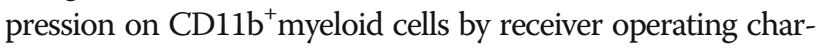
acteristic (ROC) analysis and Youden Index values (Additional file 2: Fig. S2C and S2D). The cut-off value was $3.8 \%$. Patients of $\mathrm{CD} 6^{+}$group or $\mathrm{CD} 16^{\text {low }}$ group were determined if their frequencies of $\mathrm{CD}_{11} \mathrm{~b}^{+} \mathrm{CD} 16^{\text {high }}$ cells were higher or lower than the cut-off value (Additional file 2: Fig. S2B, S2C and S2D). Then we assessed correlations between the expression level of CD16 and CRC clinicopathological characteristics by $x^{2}$ test. The data revealed that patients in $\mathrm{CD} 16^{\text {low/- }}$ group had more cancer recurrence $(P=0.042)$ and high level of carcinoembryonic antigen (CEA) $(P=$ $0.023)$ as well as carbohydrate antigen 199 (CA199) $(P=$
0.016) compared to patients in $\mathrm{CD}_{16}{ }^{+}$group (Table 2). There were 18 CRC patients (78.26\%) developing recurrent tumor in CD16 ${ }^{\text {low/- }}$ group, whereas only 5 cases $(21.74 \%)$ were observed in $\mathrm{CD}^{+} 6^{+}$group. Among $20 \mathrm{CRC}$ patients with high CEA level, 15 patients (75\%) belonged to CD16 $6^{\text {low/- }}$ group, while only 5 patients $(25 \%)$ were $\mathrm{CD}^{+}{ }^{+}$. And 14 patients (77.78\%) with high CA199 level were found in CD16 $16^{\text {low/- }}$ group compared with 4 cases $(22.22 \%)$ in that of $\mathrm{CD}_{16}{ }^{+}$. However, no significant difference was observed between these two groups on age, gender, tumor location, tumor size and Tumor Node Metastasis (TNM) stage (Table 2).

To further confirm these results, we divided 134 CRC patients after capecitabine treatment into two groups based on the level of CEA or CA199, and compared the expression level of CD16 on $\mathrm{CD} 11 \mathrm{~b}^{+} \mathrm{CD} 16^{+}$myeloid cells between CEA-high (CEA $>5 \mathrm{ng}$ ) and CEA-low (CEA $\leq 5$

Table 2 Relationship between CD16 expression on CD11 b ${ }^{+}$myeloid cells after capecitabine therapy and clinicopathologic characteristics

\begin{tabular}{|c|c|c|c|c|c|c|c|}
\hline \multirow[t]{2}{*}{ Characteristics } & \multicolumn{2}{|c|}{ All patients $(\boldsymbol{n}=134)$} & \multicolumn{2}{|c|}{$\mathrm{CD}_{16}{ }^{+}$after therapy $(\boldsymbol{n}=65,48.51 \%)$} & \multicolumn{2}{|c|}{ CD16 ${ }^{\text {low/- }}$ after therapy $(\boldsymbol{n}=69,51.49 \%)$} & \multirow{2}{*}{$\begin{array}{l}\boldsymbol{P} \\
\text { value }\end{array}$} \\
\hline & $\mathrm{n}$ & $\%$ & $\mathrm{n}$ & $\%$ & $n$ & $\%$ & \\
\hline \multicolumn{8}{|l|}{ Age (years) } \\
\hline$<65$ & 70 & $52.24 \%$ & 36 & $51.43 \%$ & 34 & $48.57 \%$ & \multirow[t]{2}{*}{0.479} \\
\hline$\geq 65$ & 64 & $47.76 \%$ & 29 & $45.31 \%$ & 35 & $54.69 \%$ & \\
\hline \multicolumn{8}{|l|}{ Gender } \\
\hline Male & 82 & $61.19 \%$ & 42 & $51.22 \%$ & 40 & $48.78 \%$ & \multirow[t]{2}{*}{0.43} \\
\hline Female & 52 & $38.81 \%$ & 23 & $44.23 \%$ & 29 & $55.77 \%$ & \\
\hline \multicolumn{8}{|l|}{ Tumor location } \\
\hline Rectum & 68 & $50.75 \%$ & 32 & $47.06 \%$ & 36 & $52.94 \%$ & \multirow[t]{2}{*}{0.733} \\
\hline Colon & 66 & $49.25 \%$ & 33 & $50.00 \%$ & 33 & $50.00 \%$ & \\
\hline \multicolumn{8}{|l|}{ Tumor Size } \\
\hline$\geq 5 \mathrm{~cm}$ & 57 & $42.54 \%$ & 25 & $43.86 \%$ & 32 & $56.14 \%$ & \multirow[t]{2}{*}{0.354} \\
\hline$<5 \mathrm{~cm}$ & 77 & $57.46 \%$ & 40 & $51.95 \%$ & 37 & $48.05 \%$ & \\
\hline \multicolumn{8}{|c|}{ CEA level after therapy } \\
\hline$\leq 5 \mathrm{ng} / \mathrm{ml}$ & 114 & $85.07 \%$ & 60 & $52.63 \%$ & 54 & $47.37 \%$ & \multirow[t]{2}{*}{0.023} \\
\hline$>5 \mathrm{ng} / \mathrm{ml}$ & 20 & $14.93 \%$ & 5 & $25.00 \%$ & 15 & $75.00 \%$ & \\
\hline \multicolumn{8}{|c|}{ CA199 level after therapy } \\
\hline$\leq 27 \mathrm{ng} / \mathrm{ml}$ & 116 & $86.57 \%$ & 61 & $52.59 \%$ & 55 & $47.41 \%$ & \multirow[t]{2}{*}{0.016} \\
\hline$>27 \mathrm{ng} / \mathrm{ml}$ & 18 & $13.43 \%$ & 4 & $22.22 \%$ & 14 & $77.78 \%$ & \\
\hline \multicolumn{8}{|l|}{ TNM stage (AJCC) } \\
\hline Stage ॥ & 98 & $73.13 \%$ & 45 & $45.92 \%$ & 53 & $54.08 \%$ & \multirow[t]{2}{*}{0.322} \\
\hline Stage III & 36 & $26.87 \%$ & 20 & $55.56 \%$ & 16 & $44.44 \%$ & \\
\hline \multicolumn{8}{|c|}{ Location of recurrence } \\
\hline Loco-regional & 3 & $13.04 \%$ & 2 & $40.00 \%$ & 1 & $5.56 \%$ & \multirow[t]{5}{*}{0.042} \\
\hline liver + lung & 3 & $13.04 \%$ & 2 & $40.00 \%$ & 1 & $5.56 \%$ & \\
\hline liver & 10 & $43.48 \%$ & 1 & $20.00 \%$ & 9 & $50.00 \%$ & \\
\hline lung & 6 & $26.09 \%$ & 0 & $0.00 \%$ & 6 & $33.33 \%$ & \\
\hline peritoneum & 1 & $4.35 \%$ & 0 & $0.00 \%$ & 1 & $5.56 \%$ & \\
\hline
\end{tabular}


ng) groups, or between CA199-high (CA199>27 ng) and CA199-low (CA199 $\leq 27 \mathrm{ng}$ ) groups. The boundary value of CEA and CA199 were decided by clinical guidelines. The results showed that the expression level of CD16 was dramatically decreased in either CEA-high or CA199-high groups compared to CEA-low or CA199low groups (Fig. 2a and b), suggesting that the decreased

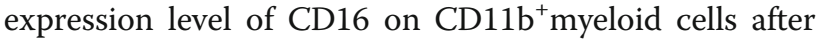
capecitabine treatment was related to the poor pathological features. In conclusion, low level of CD16 expression was related to poor pathological features, such as tumor recurrence, CEA and CA199, in CRC patients with capecitabine therapy.

\section{CD16 serves as a prognostic marker for CRC patients received capecitabine adjuvant chemotherapy}

To further explore the prognostic significance of CD16 expression on $\mathrm{CD}_{11} \mathrm{~b}^{+}$myeloid cells in predicting the treatment efficacy of capecitabine chemotherapy, we compared the differences of overall survival (OS) and disease free survival (DFS) between $\mathrm{CD}_{16}{ }^{+}$group and $\mathrm{CD} 16^{\text {low/- }}$ group. The survival curves revealed that there were significant association between the expression level of CD16 and OS $(P=0.0006)$ (Fig. 3a) or DFS $(P=$ 0.0023)(Fig. 3b), suggesting that low expression level of CD16 was associated with shorter survival. Next, we used univariate analysis to further elucidate the significance of CD16 expression in predicting prognosis of CRC patients receiving capecitabine. The result demonstrated that CD16 expression level $(P=0.011, \mathrm{HR}=$ $0.395)$ was prognostic factor for OS (Table 3 ). What's important, Cox multivariate analysis also demonstrated that expression level of $\mathrm{CD} 16(P=0.049, \mathrm{HR}=2.13)$ was still independent predictors of OS (Table 3$)$. These results demonstrated that the expression level of CD16

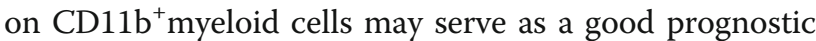
marker for overall survival in CRC patients with capecitabine adjuvant chemotherapy.

\section{Down-regulation of CD16 expression on CD11 $\mathrm{b}^{+}$myeloid cells appears earlier than diagnosis of capecitabine by imaging tests}

As we know, adjuvant chemotherapy remains the first line therapy for CRC patients. Capecitabine, the oral prodrug of 5-fluorouracil, is one of the primary drugs for the treatment. A number of CRC patients become insensitive to the therapy and suffer from cancer recurrence. In clinic, capecitabine-resistance is mainly diagnosed by cancer recurrence discovered through colonoscopy or CT scan in about 2-3 years after capecitabine treatment [18]. Next, we wondered if the change of CD16 expression level on $\mathrm{CD}_{11 \mathrm{~b}^{+} \text {myeloid }}$ cells appeared earlier than $\mathrm{CT}$-showed recurrence. We selected CRC patients with capecitabine treatment whose blood samples were examined before and after capecitabine treatment (Table 1). The results showed in $90 \%$ patients in capecitabine-resistant group, the

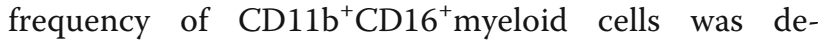
creased 6-9 months after treatment compared to that before treatment (Fig. 1a), while capecitabine resistance was diagnosed by CT scan about 2 years after the treatment (Table 1 and Additional file 1: Fig. S1E). What's important, in a resistant patient, decreased expression level of CD16 was found as early as 1 month after capecitabine treatment (Fig. 4a). The frequency of $\mathrm{CD}_{11} \mathrm{~b}^{+} \mathrm{CD} 16^{\text {high }}$ cell population was largely lower than the cut-off value (3.8\%). Nevertheless, 15 months after the capecitabine therapy, tumor
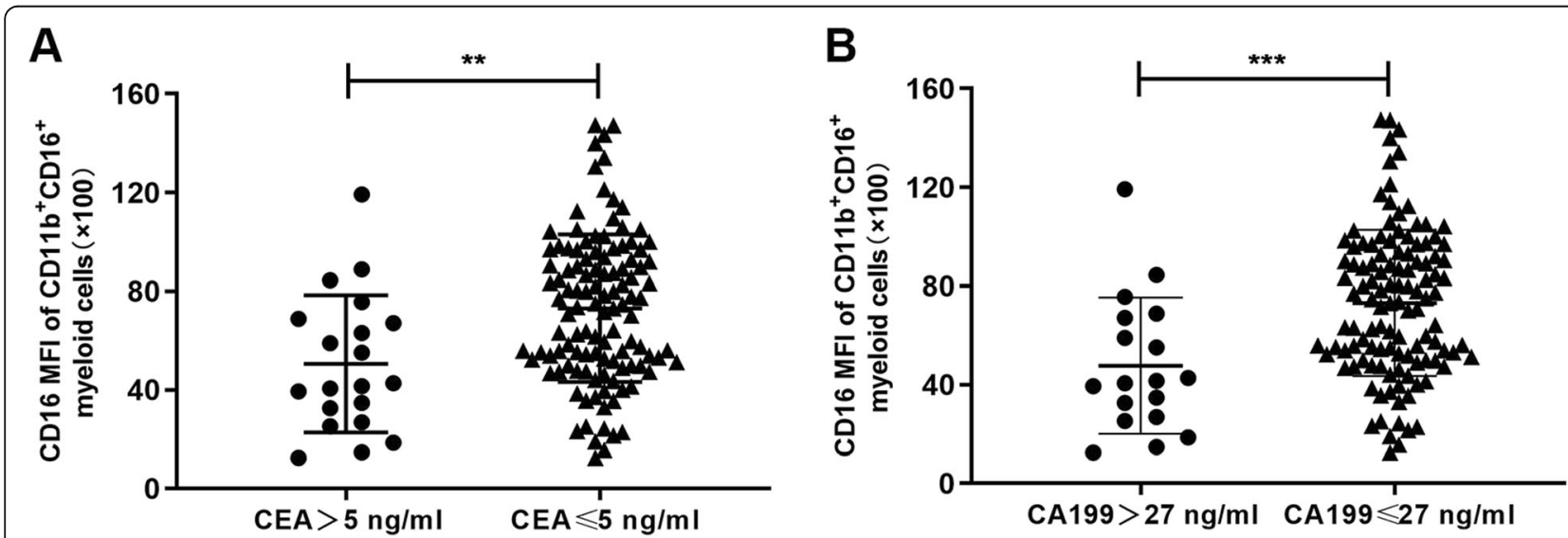

Fig. $2 \mathrm{CD} 16$ expression of $\mathrm{CD} 11 \mathrm{~b}^{+} \mathrm{CD} 16^{+}$myeloid cells related to pathological features of $\mathrm{CRC}$ patients with capecitabine therapy. CRC patients receiving capecitabine therapy were divided into different groups according to their CEA or CA199 level ( $n=20$ in CEA-high (CEA > 5 ng) group and $n=114$ in CEA-low (CEA $\leq 5 \mathrm{ng}$ ) group, $n=18$ in CA199-high (CA199>27 ng) group and $n=116$ in CA199-low (CA199 $\leq 27 \mathrm{ng})$ group). CD16 $\mathrm{MFI}$ of $\mathrm{CD} 11 \mathrm{~b}^{+} \mathrm{CD} 16^{+}$myeloid cells in CRC patients acquired from flow cytometry analysis was compared between different groups. Mean $\pm \mathrm{SEM}$, ${ }^{*} P<0.01,{ }^{* * *} P<0.001$ by $t$ tests $(\mathbf{a}, \mathbf{b})$ 


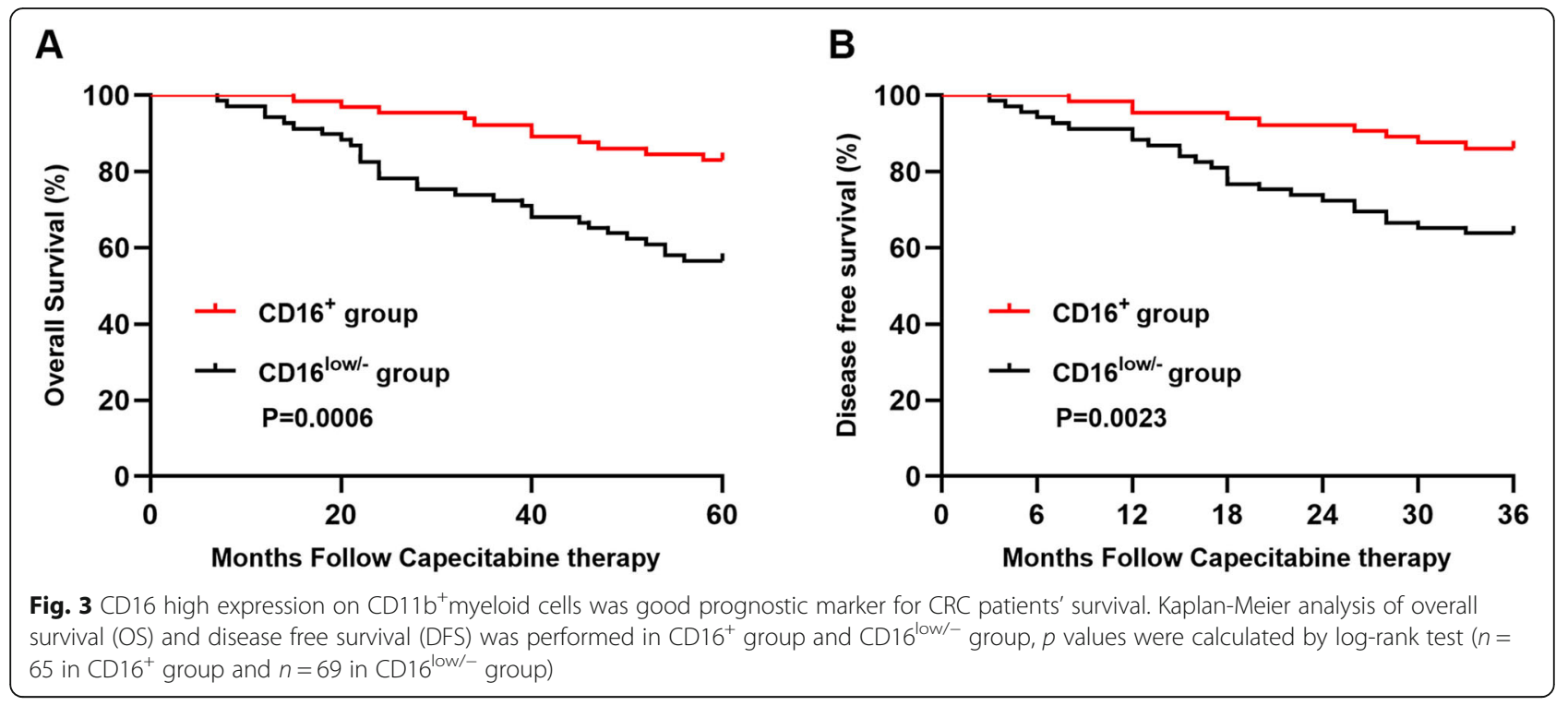

recurrence was found in the liver from CT scan (Fig. 4b). These data suggested that down-regulation of CD16

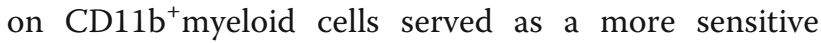
examine than CT in CRC patients treated with capecitabine.

\section{$\mathrm{CD} 11 \mathrm{~b}^{+} \mathrm{CD} 16^{\text {low/- }}$ myeloid cells are mainly immature} neutrophils after capecitabine therapy

To further characterize the population of $\mathrm{CD} 11 \mathrm{~b}^{+} \mathrm{CD} 16^{\text {low/-- }}$ myeloid cells, we isolated $\mathrm{CD} 11 \mathrm{~b}^{+} \mathrm{CD} 16^{+}$myeloid cells from capecitabine-sensitive patients and $\mathrm{CD}_{11} \mathrm{~b}^{+} \mathrm{CD} 16^{-}$myeloid cells from capecitabine-resistant patients after capecitabine therapy (Fig. 5a). The data from flow cytometry revealed that these two populations were mainly neutrophils proved by their CD15 and CD66b expression (Additional file 3: Fig. S3A). To further verify these $\mathrm{CD} 11 \mathrm{~b}^{+} \mathrm{CD} 16^{-}$myeloid cells and $\mathrm{CD} 11 \mathrm{~b}^{+} \mathrm{CD} 16^{+}$myeloid cells were both neutrophils, we sorted these cells from capecitabine- resistant patients and capecitabine-sensitive patients, respectively. Characteristics of these patients were listed in Additional file 4: Table S1. We compared our data of RNA sequencing with published data of neutrophils from Jiang $\mathrm{K}$ et al. [30] using gene set enrichment analysis (GSEA). The results revealed that, in gene sets of neutrophil signature, the expression pattern of these cells was similar to that of the neutrophils provided by other group (Additional file 3: Fig. S3B, Additional file 5: Table S2). Nevertheless, the decline of CD15 and CD66b expression, combine with the elevation of hematopoietic progenitor-related markers, especially CD33 and CD117, suggested that these $\mathrm{CD} 11 \mathrm{~b}^{+} \mathrm{CD} 16^{-}$myeloid cells in capecitabineresistant patients became more immature after the therapy compared with $\mathrm{CD} 11 \mathrm{~b}^{+} \mathrm{CD} 16^{+}$myeloid cells from capecitabine-sensitive patients (Fig. 5b). The data of RNA sequencing also revealed declined expression of some

Table 3 Univariate and multivariate analyses for survival in CRC patients after capecitabine therapy

\begin{tabular}{|c|c|c|c|c|c|c|}
\hline \multirow{2}{*}{$\begin{array}{l}\text { Prognostic } \\
\text { parameter }\end{array}$} & \multicolumn{3}{|c|}{ Univariate analysis } & \multicolumn{3}{|c|}{ Multivariate analysis } \\
\hline & $\mathrm{HR}$ & $95 \% \mathrm{Cl}$ & $p$ value & $\mathrm{HR}$ & $95 \% \mathrm{Cl}$ & $\boldsymbol{p}$ value \\
\hline CD16 expression & 0.395 & $0.194-0.808$ & 0.011 & 2.130 & $0.227-0.998$ & 0.049 \\
\hline Gender & 1.049 & $0.534-2.064$ & 0.889 & - & - & - \\
\hline Age & 0.768 & $0.393-1.501$ & 0.441 & - & - & - \\
\hline Tumor location & 0.911 & $0.469-1.768$ & 0.783 & - & - & - \\
\hline Tumor size & 1.102 & $0.567-2.144$ & 0.774 & - & - & - \\
\hline CEA & 2.410 & $1.093-5.313$ & 0.029 & 1.868 & $0.831-4.201$ & 0.131 \\
\hline CA199 & 1.624 & $0.674-3.914$ & 0.280 & - & - & - \\
\hline TNM & 1.443 & $0.707-2.947$ & 0.314 & - & - & - \\
\hline Recurrence & 2.516 & $1.207-5.243$ & 0.014 & 2.130 & $1.012-4.484$ & 0.046 \\
\hline
\end{tabular}




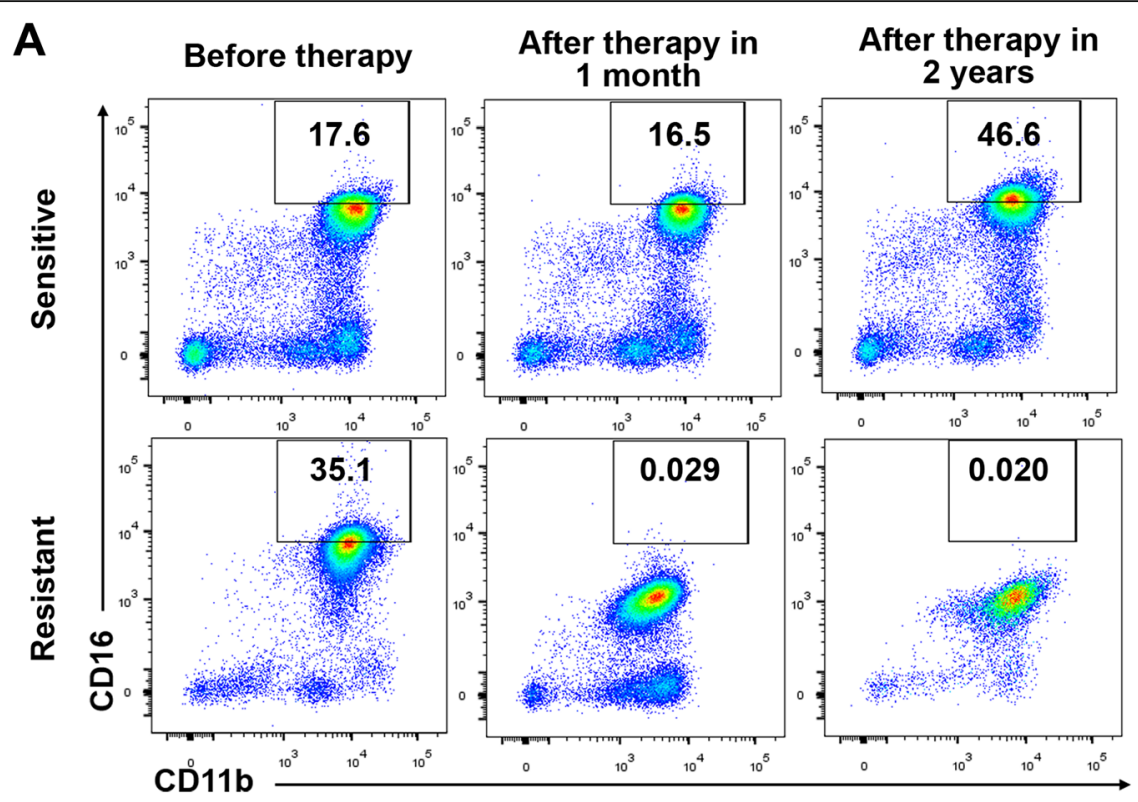

B
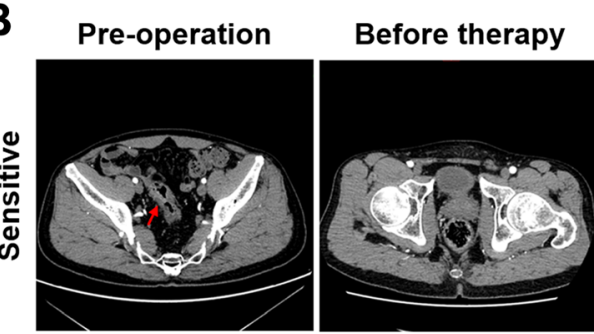

In 1 month

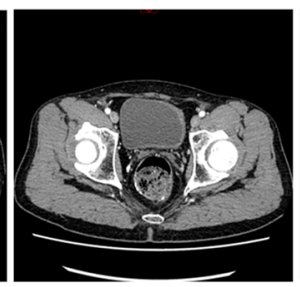

In 2 years
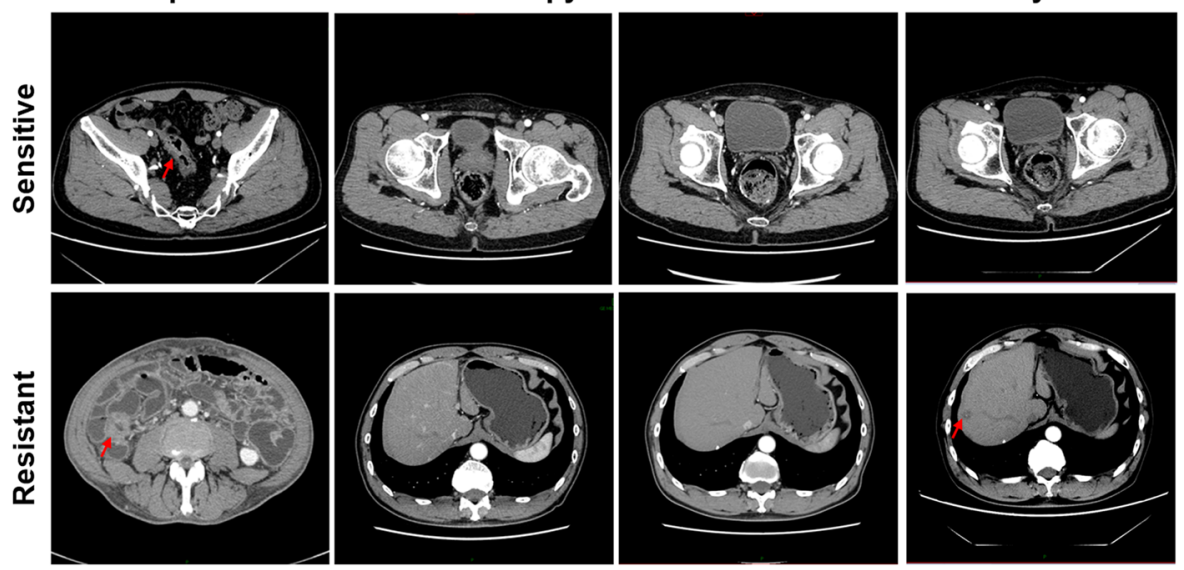

Fig. 4 Analysis of CD16 expression was more sensitive than CT scan after capecitabine therapy. a Peripheral venous blood from CRC patients receiving single-agent oral capecitabine adjuvant therapy was collected at different time (before capecitabine therapy, 1 month and 2 years after the therapy). Frequencies of $\mathrm{CD} 11 \mathrm{~b}^{+} \mathrm{CD} 16^{\text {high }}$ myeloid cells were analyzed by flow cytometry. $\mathbf{b}$ CT scan was performed during follow-up after adjuvant chemotherapy in same patients as that of (a) respectively. Sensitive patient, normal operation site with no recurrence. Resistant patient, resectable metachronous liver metastases (red arrows)

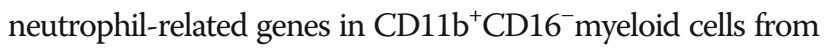
capecitabine-resistant patients after capecitabine therapy, which implied immature status of these neutrophils (Fig. 5c). In addition, active metabolism of nitrogen species, purine nucleoside and ATP were also found in these $\mathrm{CD} 11 \mathrm{~b}^{+} \mathrm{CD} 16^{-}$myeloid cells, which are tightly related to immunosuppressive role of MDSC [24, 30] (Fig. 5d). To verify the immunosuppressive role of these $\mathrm{CD} 11 \mathrm{~b}^{+} \mathrm{CD} 16^{-}$myeloid cells, we sorted peripheral blood $\mathrm{CD} 11 \mathrm{~b}^{+} \mathrm{CD} 16^{-}$myeloid cells from capecitabine-resistant CRC patients, and

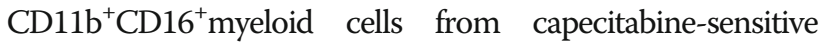
CRC patients or HDs, and autologous T cells as well. After coculture $\mathrm{T}$ cells with these myeloid cells in the presence of leukocyte activators, proliferation of $\mathrm{T}$ cell was significantly declined in resistant CRC patients group, compared with single $\mathrm{T}$ cell group, HD group and sensitive CRC patients group (Fig. 5e). The results suggested that these

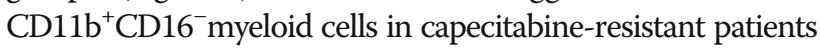
might exert immature cell status and play immunosuppressive role like MDSC.

The low expression level of CD16 on neutrophils is related to pro-tumor status in CRC patients after capecitabine therapy

As we know, immature myeloid cells are usually MDSCs, which could exert powerful immunosuppressive role, 


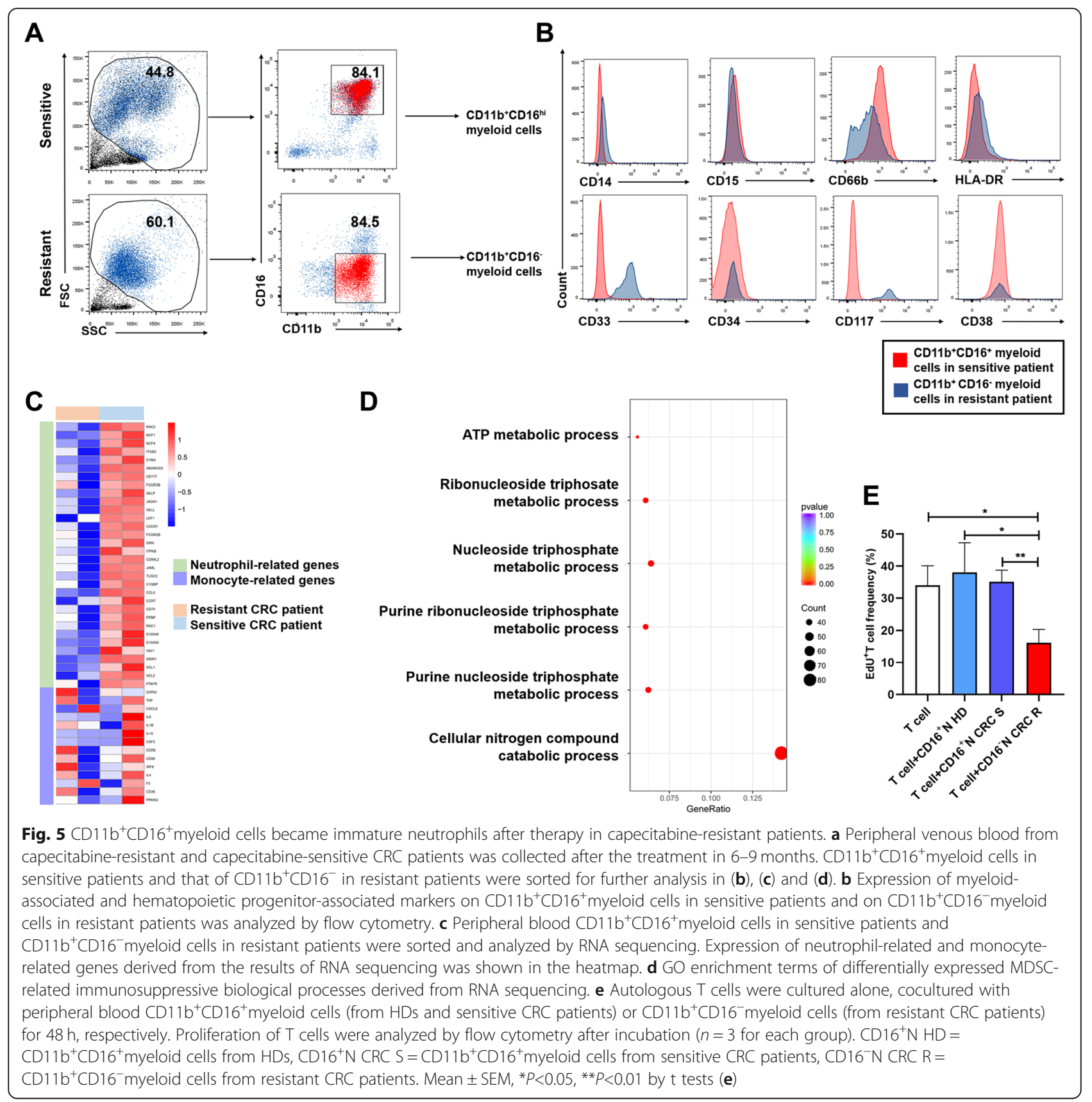

especially in inhibiting T cells and NK cells $[24,25,30]$.

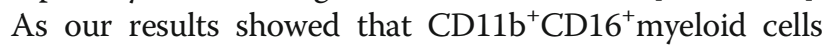
from capecitabine-sensitive patients and $\mathrm{CD}_{11} \mathrm{~b}^{+} \mathrm{CD} 16^{-}$myeloid cells from capecitabine-resistant patients were mainly neutrophils, we tried to find out the relationship between the expression level of CD16 on neutrophils and other major immune cell subsets. We collected peripheral venous blood from colorectal cancer patients 6-9 months after capecitabine therapy and analyzed frequencies of immune cells by flow cytometry. The relationships between expression level of CD16 on neutrophils and frequencies of immune cell subsets were analyzed by Pearson's correlation test. The results showed that $\mathrm{CD} 16$ expression was positively related to $\mathrm{CD} 8^{+} \mathrm{T}$ cell, $\mathrm{CD}^{+} \mathrm{T}$ cell, monocyte and NK cell frequencies (Fig. 6a, b, $\mathrm{c}$ and $\mathrm{d}$ ), but not that of $\mathrm{CDC}$ and $\mathrm{pDC}$ in patients after capecitabine therapy (Fig. 6e and f), suggesting that $\mathrm{CD} 16^{\text {low/-}}$ neutrophils might have immunosuppressive activity as MDSCs.

\section{Discussion}

Over the past few decades, numerous researchers have attempted to improve the efficacy of capecitabine adjuvant therapy to ameliorate prognosis of CRC patients. 


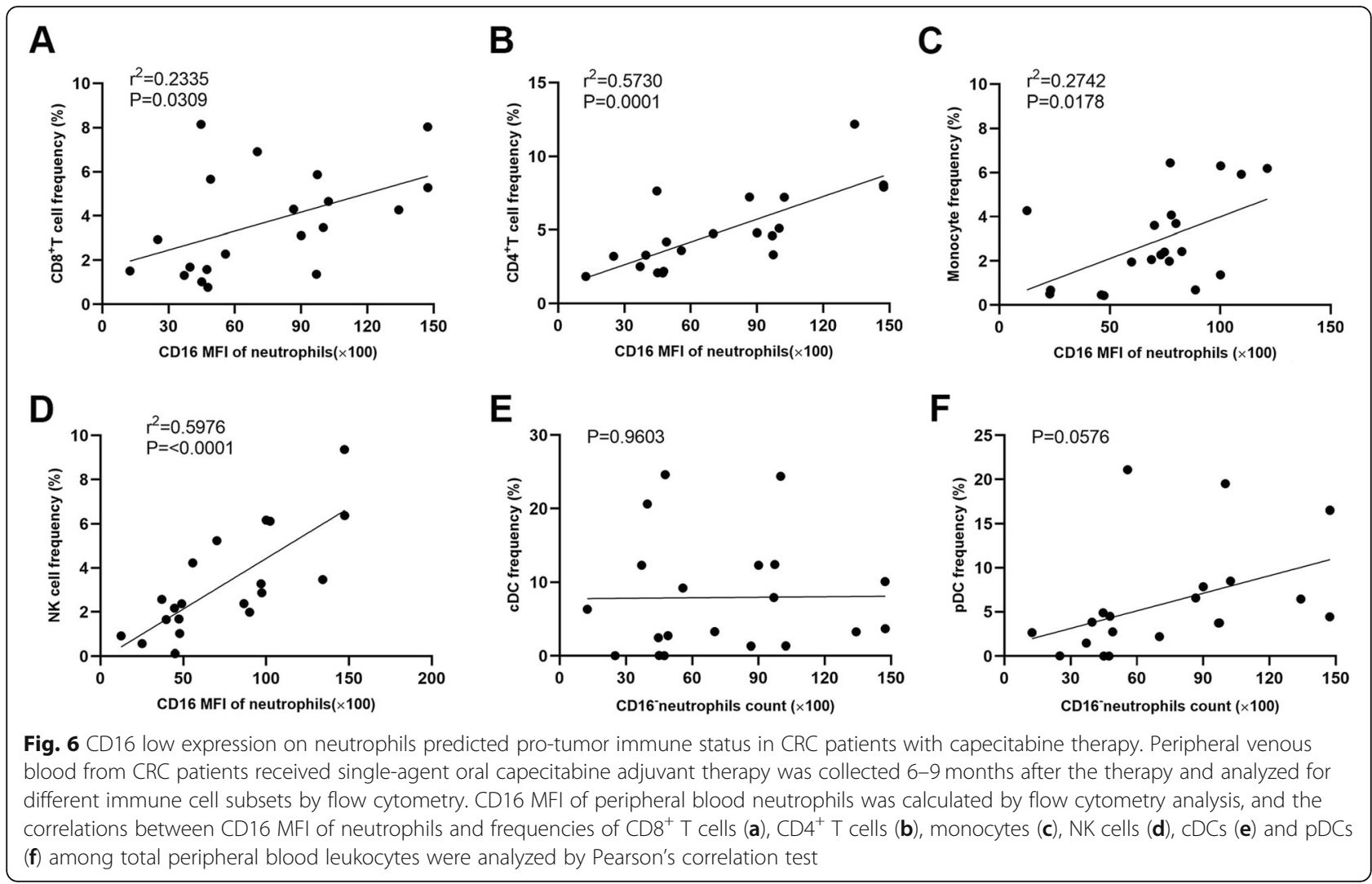

However, it remains one of the principal obstacle for cancer therapy at present. In this study, we demonstrated that the expression level of CD16 was downregulated in capecitabine-resistant patients and lower expression level of CD16 on neutrophils in peripheral blood was correlated with poor prognosis in CRC patients with capecitabine adjuvant therapy. Importantly, down-regulation of CD16 was observed as early as 1 month after capecitabine treatment, which was more sensitive than CT scan, indicating its great value in clinical application. We determined the cut-off value of CD16 expression (3.8\%) on neutrophils for the prediction of capecitabine chemoresistance, which would be helpful for clinical application and further researches. Analyzation of these $\mathrm{CD} 16^{\mathrm{low} /-}$ neutrophils in capecitabine-resistant patients revealed their immature status, and the expression of CD16 on neutrophils was positively correlated with frequencies of anti-tumor immune cell populations.

To this day, coloscopy and CT scan are still the main examines to supervise CRC progression and discover recurrence, which is vital for capecitabineresistance diagnosis. Unfortunately, these two methods could only provide evidence until tumors are big enough to be discovered, patients won't have enough time to adjust the treatment. CEA and CA199 are widely used to CRC surveillance as well, especially CEA [31]. However, CEA and CA199 cannot predict cancer progression so precisely, and the false positive or negative results will lead to anxiety and excessive therapy. What's more, some clinical trial also suggested that combining CEA and CT got no advantage compared with single examine [32]. In this study, our results showed that CD16 expression could serve as a good prognostic marker for poor CRC progression after capecitabine therapy. Analyzation of CD16 expression has great advantages. First, the downregulation of CD16 expression on neutrophils could be observed at the early stage of capecitabineresistance after the treatment (Fig. 4). Previous studies have demonstrated that $85 \%$ CRC patients had primary resistance to 5 -FU single treatment $[12,13]$, thus the marker is essential for the drug-selection in these patients. Second, this marker is quite accurate for predicting capecitabine-resistance after the therapy. In our study, we collected totally 134 CRC patients with capecitabine therapy to examine the expression level of CD16 on neutrophils. Among 23 patients who were diagnosed as capecitabineresistance, $78 \%$ patients were observed to have down- 
regulation of CD16 in 6-9 months after capecitabine treatment (Table 2). Third, the examination of CD16 expression only takes about $3 \mathrm{ml}$ peripheral blood, and it is noninvasive and has nearly no effect on patients' health.

Capecitabine, the oral form of 5-FU, which is widely used in CRC therapy, has only modest efficacy due to the chemoresistance. Great efforts have been taken to find out the mechanism. Previous studies mainly concentrated on tumor cells themselves, such as expression of specific genes or generation of particular tumor cells $[33,34]$. In this research, we worked on the correlation between changes on immune system and capecitabine chemoresistance, and illustrated the conversion from neutrophils to immunosuppressive, PMN-MDSC-like neutrophils in these capecitabine insensitive patients by RNA sequencing and flow cytometry. Our conclusion could also be supported by other studies, that 5-FU could promote MDSC pro-tumor function. The study by Bruchard $\mathrm{M}$ et al. found that 5-FU could activate NLRP3 inflammasome in MDSC and promote tumor growth [27]. Gobbo J et al. also discovered that 5-FU facilitated production of tumor-derived HSP70 exosomes, which favored MDSC activation [28]. Thus, prevention of MDSC function after capecitabine, or 5-FU therapy holds great promise for improving drug efficacy.

Researchers have revealed that $\mathrm{CD} 16^{+}$myeloid cells were tightly related to CRC development [35, 36]. Giulio $\mathrm{S}$ et al. found that $\mathrm{CD} 16^{+}$myeloid cell infiltration in CRC tumor tissue represented favorable prognosis [35], and by using in vitro studies, these studies also demonstrated that colon cancer infiltrate neutrophils enhance the responsiveness of $\mathrm{CD}^{+} \mathrm{T}$ cells by $\mathrm{T}$-cell receptor triggering [36]. Our work differed from theirs in some ways. Firstly, our study focused on CRC patients who received capecitabine adjuvant treatment after surgery, while Giulio Spagnoli group focused on all CRC patients and some healthy donors. Secondly, biopsies from different positions were analyzed. Peripheral blood was used in our study, while Giulio Spagnoli group mainly focused on tumor biopsies. Except these differences, some of our results were also consistent with studies from Giulio Spagnoli group. Firstly, both our data and Giulio Spagnoli group's data found that phenotype of peripheral blood $\mathrm{CD}_{11 \mathrm{~b}^{+}} \mathrm{CD} 16^{+}$myeloid cells had no difference between healthy donors and CRC patients without capecitabine therapy (Fig. S1F and G). Secondly, our work indicated that CD16 high/positive expression after capecitabine therapy predicted sensitivity to the therapy and good prognosis. These results were consistent with the work from Giulio Spagnoli group, that $\mathrm{CD}_{16}{ }^{+}$myeloid cells related to good prognosis of CRC patients.
MDSCs are a heterogeneous population of myeloid cells stay at different stages of differentiation. PMNMDSCs are a great part of MDSCs that could be considered as counterparts of immature granulocytes, chiefly immature neutrophils [23]. In this study, we found down-regulation of CD16 expression on myeloid cells in capecitabine-insensitive CRC patients after capecitabine treatment. These $\mathrm{CD} 16^{\text {low/- }}$ myeloid cells after the therapy were mainly immature neutrophils. CD16 is a low affinity $\mathrm{Fc} \gamma$ receptor, which could activate antibodydependent process like phagocytosis in neutrophils and other phagocytes [37]. It is expressed on neutrophils during the maturation. Researchers also revealed that CD16 is typically associated with PMN activation and phagocytosis, and its expression will change in different maturation status [38, 39]. MDSCs could exert protumor roles, mainly through inhibition of effective $\mathrm{T}$ cells and NK cells $[24,25]$. Our study demonstrated that low expression of CD16 on neutrophils after the therapy was related to decreased frequencies of anti-tumor immune cells, like $\mathrm{CD} 8^{+} \mathrm{T}$ cells and $\mathrm{NK}$ cells, suggesting that they may have immunosuppressive activity as MDSCs. The mechanism underlying the changes induced by capecitabine would be investigated further, and it could be a good target to compete against capecitabine chemoresistance.

\section{Conclusions}

In conclusion, CD16 seems to be a promising target for CRC progression surveillance after capecitabine therapy. Studies of CD16 expression on neutrophils may light the path for not only predicting prognosis but also solving capecitabine resistance in CRC patients.

\section{Methods}

\section{Patients and peripheral blood}

Peripheral venous blood of CRC patients in Department of Gastrointestinal Surgery, Renji Hospital (Shanghai, China) from January 2012 to December 2018 was gotten before capecitabine adjuvant treatment and at different time after the treatment (as indicated in figure legend). Peripheral venous blood of healthy donors was gotten in Renji Hospital. The pathological information of 134 patients was retrieved from the Pathology Department of Renji Hospital. These peripheral blood was used for flow cytometric analysis. All the patients were provided with written informed consent before enrolment, and the study was approved by the Research Ethics Committee of Shanghai Jiao Tong University School of Medicine Renji Hospital (Approval No. Renji [2013] N013). None of patients had received radiotherapy or chemotherapy before surgery. All patients were followed-up until death or until the final follow-up (May 2019). 


\section{Flow cytometry analysis}

Peripheral venous blood samples were subjected to density centrifugation using Ficoll-hypaque solution to isolate mononuclear cells and granulocytes. Cell suspension was treated with BD Pharm Lyse lysing solution for red blood cell lysing. To determine the frequency of different subsets myeloid cell subsets, these cells $\left(10^{\wedge} 6\right.$ cells/tube) were stained by monoclonal antibodies BB515 Rat anti-CD11b (BD Biosciences, Clone \# M1/70), PE Mouse anti-human CD66b (BD Biosciences, Clone \# G10F5) or PE mouse IgM $\mathrm{k}$ isotype control (BD Biosciences, Clone \# G155-228), BV650 mouse anti-human CD16 (BD Biosciences, Clone \# 3G8), PerCP-Cy5.5 mouse anti-human CD15 (BD Biosciences, Clone \# HI98) or PerCP-Cy5.5 mouse IgM $\mathrm{K}$ isotype control (BD Biosciences, Clone \# G155-228), PE-Cy7 mouse anti-human CD14 (BD Biosciences, Clone \# M5E2) and BV421 mouse antihuman CD33 (BD Biosciences, Clone \# WM53) at $4{ }^{\circ} \mathrm{C}$ for $30 \mathrm{~min}$ respectively. Flow cytometry was performed on an LSRFortessa (BD Biosciences) and analyzed using FlowJo Version X (Tree Star, Inc).

\section{Myeloid cells immunosuppressive activity assay}

Peripheral blood $\mathrm{CD} 11 \mathrm{~b}^{+} \mathrm{CD} 16^{-}$myeloid cells (from resistant CRC patients after capecitabine therapy),

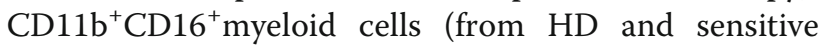
CRC patients after capecitabine therapy) and autologous $\mathrm{T}$ cells were sorted by FACS Aria II(BD Biosciences). $\mathrm{T}$ cells were either cultured alone, or cocultured with sorted myeloid cells at the ratio 2:1 $\left(5 \times 10^{5} / \mathrm{ml}\right.$, respectively) in RPMI 1640 medium with $10 \%$ FBS. Anti-CD3/CD28 stimulation beads (Invitrogen) and $100 \mathrm{u} / \mathrm{ml} \mathrm{IL-2} \mathrm{(Peprotech)} \mathrm{were} \mathrm{added} \mathrm{to}$ stimulate $\mathrm{T}$ cells. After $48 \mathrm{~h}, \mathrm{~T}$ cells were staining with $10 \mathrm{mM}$ EdU (Abcam) and cultured for another $24 \mathrm{~h}$. $\mathrm{T}$ cell proliferation was analyzed by flow cytometry.

\section{RNA sequencing}

Peripheral venous blood samples was subjected to density centrifugation using Ficoll-hypaque solution to isolate mononuclear cells and granulocytes. After lysing RBCs, cells were incubated with BB515 Rat anti-CD11b (BD Biosciences) and BV650 mouse anti-human CD16 (BD Biosciences) antibodies and sorted by flow cytometry using BD FACS AriaII. RNA sequencing (RNA-seq) was

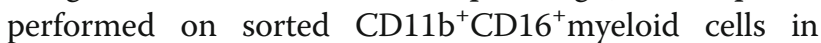

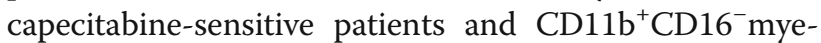
loid cells in capecitabine-resistant patients. Qubit 2.0 (Life Technologies, USA) and Bioanalyzer 2100 (Agilent, Germany) were used to analyze the RNA quality and integrity. A total of $3 \mu \mathrm{g}$ RNA was used for the RNA sample preparations. Extracted RNA samples were processed using the NEBNext ${ }^{\circ}$ UltraTM RNA Library Prep Kit (Lexogen) and sequenced on an Illumina Hiseq X-Ten with control of Hiseq Control Software (HCS). The sequencing library were qualified by Qubit 2.0 (Life technologies, USA) and Bioanalyzer 2100 (Agilent, Germany). Raw reads were processed through in-house perlscripts. Clean reads were obtained by removing reads containing adapter. Differentially expressed genes were defined by $P<0.05$ and an absolute fold change $>2$. Using Gene Set Enrichment Analysis, enrichment of a specific gene set was tested, and core enrichment genes were determined.

\section{Statistical analysis}

All analyses in this study were performed by IBM SPSS STATISTICS 22.0 software and GraphPad Prism 8 software. Statistical analysis of the data was performed using the Student's t-test and $X^{2}$ test, and results were presented as mean \pm SEM unless indicated. Unsupervised $\mathrm{K}$-means clustering of $\mathrm{CD} 11 \mathrm{~b}^{+} \mathrm{CD} 16^{\text {high }}$ cells and $\mathrm{CD} 11 \mathrm{~b}^{+} \mathrm{CD} 16^{\text {low }}$ cells, Receiver operating characteristic (ROC) and Youden Index values were used to determine cut-off value of $\mathrm{CD} 16$ expression on $\mathrm{CD} 11 \mathrm{~b}^{+} \mathrm{CD} 16^{+}$myeloid cells. Univariate and multivariate Cox regression analyses were used to identify independent prognostic factors. The results were considered statistically significant if $P<0.05$.

\section{Supplementary information}

Supplementary information accompanies this paper at https://doi.org/10. 1186/s12865-020-00375-8.

Additional file 1: Figure S1. Flow cytometry analyses of different myeloid cell subsets and representative CT scan in CRC patients. Peripheral venous blood from CRC patients received single-agent oral capecitabine adjuvant therapy was collected 6-9 months after the therapy and analyzed for myeloid cell-related markers. Frequencies of different myeloid cell subsets, including monocytes (CD11 b ${ }^{+}$CD $\left.14^{+} \mathrm{CD} 15^{-}\right)(\mathrm{A})$, neutrophils $\left(\mathrm{CD} 11 \mathrm{~b}^{+} \mathrm{CD} 15^{+} \mathrm{CD} 14^{-}\right.$or $\left.\mathrm{CD} 11 \mathrm{~b}^{+} \mathrm{CD} 66 \mathrm{~b}^{+} \mathrm{CD} 14^{-}\right)(\mathrm{B}$ and $\mathrm{C})$ and MDSC $\left(C D 11 b^{+} \mathrm{HLA}^{-D R^{-V o w}} \mathrm{CD}^{+} 3^{+}\right)(\mathrm{D})$ were compared between

capecitabine-sensitive patients and capecitabine-resistant patients $(n=26$ in capecitabine-sensitive group and $n=10$ in capecitabine-resistant group, respectively). (E) CT scan was performed before the operation and during follow-up in same patients as that of Fig. 1b. Patient 1, normal operation site and no recurrence. Patient 27 , unresectable metachronous lung metastases. Red arrows indicate primary tumor in situ or metastatic sites. (F) Peripheral blood $\mathrm{CD} 11 \mathrm{~b}^{+} \mathrm{CD} 16^{+}$myeloid cells from $\mathrm{HDs}$ and $\mathrm{CRC}$ patients before therapy were analyzed using flow cytometry. (G) CD66b, CD15, CD14, CD34 and CD117 expression on CD11 b ${ }^{+}$CD16 ${ }^{+}$myeloid cells in (F) were analyzed by flow cytometry.

Additional file 2: Figure S2. CRC patients were divided into CD16 ${ }^{+}$group and $C D 16^{\text {low }}$ group based on CD16 MFI of CD11 b $\mathrm{b}^{+}$yeloid cells. (A) Unsupervised K-means clustering of CD11 $\mathrm{b}^{+} \mathrm{CD} 16^{\text {high }}$ cells and CD $11 \mathrm{~b}^{+} \mathrm{CD} 16^{\text {low }}$ cells based on CD16 MFI of CD $11 \mathrm{~b}^{+} \mathrm{CD} 16^{+}$myeloid cells in peripheral blood $(K=2)$ after capecitabine therapy. $C D 11 b^{+} C D 16^{\text {high- }}$ cells (above red dashed line, $n=65$ ). (B) Peripheral venous blood was taken from 134 CRC patients 6-9 months after capecitabine therapy and frequencies of $C D 11 b^{+} C D 16^{\text {high }}$ cells were analyzed by flow cytometry. (C) Receiver operating characteristic (ROC) was used for determination of different cut-off values for CD16 expression level of CD11 b ${ }^{+}$myeloid cells 
based on frequencies of $C D 11 b^{+} C D 16^{\text {high }}$ cells in peripheral blood of CRC patients after capecitabine therapy. (D) Youden Index values were calculated for different cut-off values of ROC curve. Dashed line indicated the empirically chosen cut-off value for CD16 expression level of CD11 b ${ }^{+}$myeloid cells (3.8\%). Patients of $C D 16^{+}$group or $C D 16^{\text {low }}$ group were determined if their frequencies of $C D 11 b^{+} C D 16^{\text {high }}$ cells were higher or lower than the cut-off value.

Additional file 3: Figure S3. $C D 11 b^{+} C D 16^{+}$myeloid cells and CD $11 b^{+} C D 16^{-}$myeloid cells were neutrophils. (A) Peripheral venous blood from capecitabine-resistant and capecitabine-sensitive CRC patients after the therapy was collected. CD11 $\mathrm{b}^{+} \mathrm{CD} 16^{+}$myeloid cells in sensitive patients and $\mathrm{CD} 11 \mathrm{~b}^{+} \mathrm{CD} 16^{-}$myeloid cells in resistant patients were analyzed for their CD15 and CD66b expression. Meanwhile, a part of peripheral blood leukocytes from same patients were stained with mouse lgM isotype control. CD15 and CD66b expression were compared between cells stained with antibodies and that stained with isotype control. (B) The data of RNA sequencing was compared with published data of neutrophils using GSEA. Representative gene sets of neutrophil signature were shown

Additional file 4: Table S1. Baseline characteristics of CRC patients in RNA sequencing

Additional file 5: Table S2. Gene set enrichment analysis of neutrophil signature. The data of RNA sequencing was compared with published data of neutrophils using GSEA.

\section{Abbreviations}

CA: Carbohydrate antigen; CD: Cluster of differentiation;

CEA: Carcinoembryonic antigen; CRC: Colorectal cancer; CT: Computed tomography; DFS: Disease free survival; GSEA: Gene set enrichment analysis; HD: Healthy donor; MDSC: Myeloid-derived suppressor cell; MFI: Mean fluorescent intensity; OS: Overall survival; ROC: Receiver operating characteristic; TNM: Tumor Node Metastasis; 5-FU: 5-fluorouracil

\section{Acknowledgements}

We thank all patients participating in the study.

\section{Authors' contributions}

Y.Z., W.Q.G, M.Z. and Y.L. designed the research. Y.L., Y.Z.H., L.H. performed the research. Y.L. performed main experiments on the peripheral blood samples by FACS. Y.Z.H. and L.H. contributed to the peripheral blood samples selection and helped with FACS experiments. Y.L., Y.Z.H., L.H., Y.J.X., Z.E.W., H.L., and T.Z. analyzed and interpreted the FACS data and patients information. Z.Y., W.Q.G, M.Z. and Y.L. wrote the paper. All authors have read and approved the manuscript.

\section{Funding}

The study is supported by funds to Y.Z. from the National Natural Science Foundation of China (NSFC, 81773250 and 81972670), to Y.Z. from Shanghai Municipal Education Commission (ZXWF082101), to M.Z. from (NSFC, 81873555 and 81672347). The funder played no role in experimental design, data analysis or preparation of the manuscript.

\section{Availability of data and materials}

The majority of the data used to support the findings of this study are included in the article and additional files. The rest data are available from the corresponding author upon request.

\section{Ethics approval and consent to participate}

The study was approved by the Research Ethics Committee of Shanghai Jiao Tong University School of Medicine Renji Hospital. All the patients were provided with written informed consent before enrolment.

\section{Consent for publication}

Patients have consented to publish their data and photographs. All patients have written informed consent.

\section{Competing interests}

The authors declare no competing interest.

\section{Author details}

State Key Laboratory of Oncogenes and Related Genes, Renji-Med X Stem Cell Research Center, Renji Hospital, School of Medicine, Shanghai Jiaotong University, Shanghai, China. ${ }^{2}$ Department of Gastrointestinal Surgery, Renji Hospital, School of Medicine, Shanghai Jiaotong University, Shanghai, China. ${ }^{3}$ Med-X Research Institute \& School of Biomedical Engineering, Shanghai Jiaotong University, Shanghai, China.

Received: 10 February 2020 Accepted: 27 July 2020

Published online: 08 August 2020

\section{References}

1. Dekker E, Tanis PJ, Vleugels JLA, et al. Colorectal cancer. Lancet. 2019; 394(10207):1467-80

2. Wender RC, Brawley OW, Fedewa SA, et al. A blueprint for cancer screening and early detection: advancing screening's contribution to cancer control. CA Cancer J Clin. 2019;69(1):50-79.

3. Gupta N, Kupfer SS, Davis AM. Colorectal Cancer screening. JAMA. 2019; 321(20):2022-3.

4. Chen H, Li N, Ren J, et al. Cancer screening program in urban China (CanSPUC). Participation and yield of a population-based colorectal cancer screening programme in China. Gut. 2019;68(8):1450-7.

5. Chen W, Sun K, Zheng R, et al. Cancer incidence and mortality in China, 2014. Chin J Cancer Res. 2018;30(1):1-12.

6. Chen W, Zheng R, Baade PD, et al. Cancer statistics in China, 2015. CA Cancer J Clin. 2016:66(2):115-32.

7. Twelves C, Scheithauer W, McKendrick J, et al. Capecitabine versus 5fluorouracil/folinic acid as adjuvant therapy for stage III colon cancer: final results from the X-ACT trial with analysis by age and preliminary evidence of a pharmacodynamic marker of efficacy. Ann Oncol. 2012;23(5):1190-7.

8. No authors listed. New guideline on managing colorectal cancer. Cancer Discov. 2017;7(4):OF2.

9. Baena-Cañada JM, Martínez MJ, García-Olmedo O, et al. Interaction between capecitabine and brivudin in a patient with breast cancer. Nat Rev Clin Oncol. 2010;7(1):55-8.

10. Rosmarin D, Palles C, Church D, et al. Genetic markers of toxicity from capecitabine and other fluorouracil-based regimens: investigation in the QUASAR2 study, systematic review, and meta-analysis. J Clin Oncol. 2014;32(10):1031-9.

11. Lam SW, Guchelaar HJ, Boven E. The role of pharmacogenetics in capecitabine efficacy and toxicity. Cancer Treat Rev. 2016;50:9-22.

12. Longley DB, Harkin DP, Johnston PG. 5-fluorouracil: mechanisms of action and clinical strategies. Nat Rev Cancer. 2003;3(5):330-8.

13. Zhang N, Yin Y, Xu SJ, et al. 5-fluorouracil: mechanisms of resistance and reversal strategies. Molecules. 2008;13(8):1551-69.

14. Crea F, Nobili S, Paolicchi $E$, et al. Epigenetics and chemoresistance in colorectal cancer: an opportunity for treatment tailoring and novel therapeutic strategies. Drug Resist Updat. 2011;14(6):280-96.

15. Uppada SB, Gowrikumar S, Ahmad R, et al. MASTL induces Colon Cancer progression and Chemoresistance by promoting Wnt/ $\beta$-catenin signaling. Mol Cancer. 2018;17(1):111.

16. Touil Y, Igoudjil W, Corvaisier M, et al. Colon cancer cells escape 5FU chemotherapy-induced cell death by entering stemness and quiescence associated with the c-yes/YAP axis. Clin Cancer Res. 2014;20(4):837-46.

17. Longley DB, Johnston PG. Molecular mechanisms of drug resistance. J Pathol. 2005;205(2):275-92.

18. Sargent D, Sobrero A, Grothey A, et al. Evidence for cure by adjuvant therapy in colon cancer: observations based on individual patient data from 20,898 patients on 18 randomized trials. J Clin Oncol. 2009;27(6):872-7.

19. Gong L, Cumpian AM, Caetano MS, et al. Promoting effect of neutrophils on lung tumorigenesis is mediated by CXCR2 and neutrophil elastase. Mol Cancer. 2013;12(1):154

20. Wang $\pi$, Zhao YL, Peng LS, et al. Tumour-activated neutrophils in gastric cancer foster immune suppression and disease progression through GMCSF-PD-L1 pathway. Gut. 2017;66(11):1900-11.

21. Hamm A, Prenen $\mathrm{H}$, Van Delm W, et al. Tumour-educated circulating monocytes are powerful candidate biomarkers for diagnosis and disease follow-up of colorectal cancer. Gut. 2016;65(6):990-1000.

22. Sidibe A, Ropraz $P$, Jemelin $S$, et al. Angiogenic factor-driven inflammation promotes extravasation of human proangiogenic monocytes to tumours. Nat Commun. 2018;9(1):355. 
23. Singel KL, Segal BH. Neutrophils in the tumor microenvironment: trying to heal the wound that cannot heal. Immunol Rev. 2016;273(1):329-43.

24. Veglia F, Perego M, Gabrilovich D. Myeloid-derived suppressor cells coming of age. Nat Immunol. 2018;19(2):108-19.

25. Kumar V, Patel S, Tcyganov E, et al. The nature of myeloid-derived suppressor cells in the tumor microenvironment. Trends Immunol. 2016;37(3):208-20.

26. Vincent J, Mignot G, Chalmin F, et al. 5-fluorouracil selectively kills tumorassociated myeloid-derived suppressor cells resulting in enhanced T celldependent antitumor immunity. Cancer Res. 2010;70(8):3052-61.

27. Bruchard $M$, Mignot $G$, Derangère $V$, et al. Chemotherapy-triggered cathepsin B release in myeloid-derived suppressor cells activates the Nlrp3 inflammasome and promotes tumor growth. Nat Med. 2013;19(1):57-64.

28. Gobbo J, Marcion G, Cordonnier M, et al. Restoring anticancer immune response by targeting tumor-derived exosomes with a HSP70 peptide aptamer. J Natl Cancer Inst. 2015:108(3):1-11.

29. Yin $Y$, Yao S, Hu Y, et al. The immune-microenvironment confers Chemoresistance of colorectal cancer through macrophage-derived IL6. Clin Cancer Res. 2017;23(23):7375-87.

30. Jiang $K$, Sun $X$, Chen $Y$, et al. RNA sequencing from human neutrophils reveals distinct transcriptional differences associated with chronic inflammatory states. BMC Med Genet. 2015;8:55.

31. Michl M, Stintzing $S$, Fischer von Weikersthal L, et al. CEA response is associated with tumor response and survival in patients with KRAS exon 2 wild-type and extended RAS wild-type metastatic colorectal cancer receiving first-line FOLFIRI plus cetuximab or bevacizumab (FIRE-3 trial). Ann Oncol. 2016:27(8):1565-72.

32. Primrose JN, Perera R, Gray A, et al. Effect of 3 to 5 years of scheduled CEA and $\mathrm{CT}$ follow-up to detect recurrence of colorectal cancer: the FACS randomized clinical trial. JAMA. 2014;311(3):263-70.

33. Grassilli E, Narloch R, Federzoni E, et al. Inhibition of GSK3B bypass drug resistance of p53-null colon carcinomas by enabling necroptosis in response to chemotherapy. Clin Cancer Res. 2013;19(14):3820-31.

34. Kucerova L, Feketeova L, Kozovska Z, et al. In vivo 5FU-exposed human medullary thyroid carcinoma cells contain a chemoresistant CD133+ tumorinitiating cell subset. Thyroid. 2014;24(3):520-32.

35. Sconocchia G, Zlobec I, Lugli A, et al. Tumor infiltration by FcyRIII (CD16)+ myeloid cells is associated with improved survival in patients with colorectal carcinoma. Int J Cancer. 2011;128(11):2663-72.

36. Governa V, Trella E, Mele V, et al. The interplay between neutrophils and CD8(+) T cells improves survival in human colorectal cancer. Clin Cancer Res. 2017;23(14):3847-58

37. Owen J, Punt J, Stranford S, et al. Kuby immunology. 7th ed. New York: W. H. Freeman and Company; 2013.

38. Golay J, Valgardsdottir R, Musaraj G, et al. Human neutrophils express low levels of FcyRIIIA, which plays a role in PMN activation. Blood. 2019;133(13): 1395-405.

39. Yokoyama Y, Suzuki T, Sakata-Yanagimoto M, et al. Derivation of functional mature neutrophils from human embryonic stem cells. Blood. 2009;113(26): 6584-92.

\section{Publisher's Note}

Springer Nature remains neutral with regard to jurisdictional claims in published maps and institutional affiliations.

Ready to submit your research? Choose BMC and benefit from:

- fast, convenient online submission

- thorough peer review by experienced researchers in your field

- rapid publication on acceptance

- support for research data, including large and complex data types

- gold Open Access which fosters wider collaboration and increased citations

- maximum visibility for your research: over $100 \mathrm{M}$ website views per year

At $\mathrm{BMC}$, research is always in progress.

Learn more biomedcentral.com/submissions 